
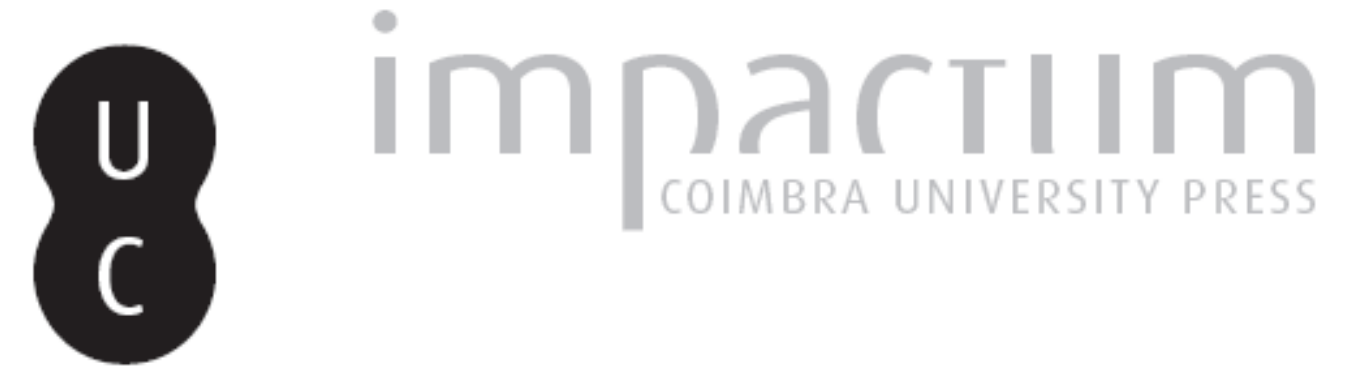

\title{
Uma forma da criatividade: criação como impossiblidade em sistemas psíquicos na sociedade contemporânea
}

Autor(es): $\quad$ Inácio, Luís Miguel Rodrigues

Publicado por: Imprensa da Universidade de Coimbra

URL persistente:

URI:http://hdl.handle.net/10316.2/35508

DOI:

DOI:http://dx.doi.org/10.14195/0870-4112_11_11

Accessed : $\quad$ 26-Apr-2023 13:28:28

A navegação consulta e descarregamento dos títulos inseridos nas Bibliotecas Digitais UC Digitalis, UC Pombalina e UC Impactum, pressupõem a aceitação plena e sem reservas dos Termos e Condições de Uso destas Bibliotecas Digitais, disponíveis em https://digitalis.uc.pt/pt-pt/termos.

Conforme exposto nos referidos Termos e Condições de Uso, o descarregamento de títulos de acesso restrito requer uma licença válida de autorização devendo o utilizador aceder ao(s) documento(s) a partir de um endereço de IP da instituição detentora da supramencionada licença.

Ao utilizador é apenas permitido o descarregamento para uso pessoal, pelo que o emprego do(s) título(s) descarregado(s) para outro fim, designadamente comercial, carece de autorização do respetivo autor ou editor da obra.

Na medida em que todas as obras da UC Digitalis se encontram protegidas pelo Código do Direito de Autor e Direitos Conexos e demais legislação aplicável, toda a cópia, parcial ou total, deste documento, nos casos em que é legalmente admitida, deverá conter ou fazer-se acompanhar por este aviso.

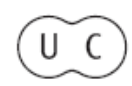




\section{ESTÉTICA E POLÍTICA}

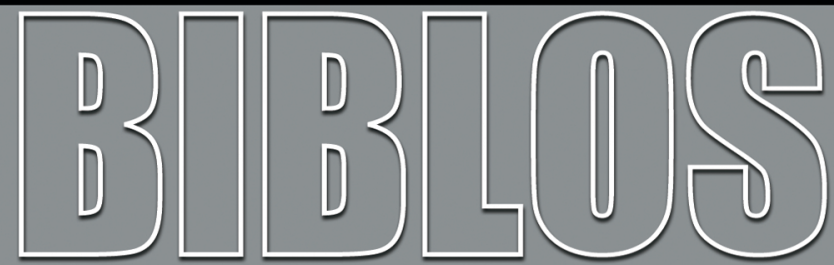

REVISTA DA FACULDADE DE LETRAS UNIVERSIDADE DE COIMBRA 
Biblos, n. s. XI (2013) 277-302

DOI: http://dx.doi.org/10.14195/0870-4112_11_11

Luís Miguel Rodrigues InÁCio

\section{UMA FORMA DA CRIATIVIDADE: CRIAÇÃO COMO IMPOSSIBILIDADE EM SISTEMAS PSÍQUICOS NA SOCIEDADE CONTEMPORÂNEA}

\section{Resumo}

A criatividade passou a ser um tema de grande importância para a sociedade contemporânea, nomeadamente no contexto da comunicação económica. Termos como "criar", "inovação", "performance", "empreendedorismo", "design", "produtividade", e termos correlativos tais como "mudança", "novo", "original", permeiam as conversas quotidianas, os discursos publicitários, e os discursos susceptíveis de alcance político e ideológico. O foco contemporâneo por esta actividade humana, realçada como essencial e discriminativa do desenvolvimento psíquico, pressionou uma diversidade de programas científicos com vista ao desenvolvimento de métodos para o acesso à criatividade.

Mas onde fica a operacionalidade da criatividade em sistemas psíquicos? É possível observar a criação? É possível a criação? Quais as dificuldades, e limites, levantadas neste contexto? Esta investigação incide directamente no questionamento do acesso à criatividade e o surgimento de uma criação. A nossa aproximação terá como como ponto de partida o sistema psíquico na base do esquema binário criatividadelcriação, investigado através das Leis da Forma de George Spencer-Brown e da teoria dos sistemas de Niklas Luhmann, numa clara tentativa de criar uma impossibilidade sobre uma indicação da criação, e a exploração do seu contraste com propostas que caracterizam, num âmbito psicologista, a "criatividade" como teleológica, intersubjectiva, representativa, composicional e progressiva.

Palavras-chave: criatividade, criação, sistema psíquico, Leis da Forma, Teoria dos Sistemas.

\footnotetext{
Abstract

Creativity has become a topic of great importance to contemporary society, particularly in the context of economic communication. Terms such as "create", "innovation", "performance", "entrepreneurship", "design", "productivity", and correlative terms such as "change", "new", "original", permeate
} 
the conversations of the everyday, of the advertising discourses, and discourses with political and ideological reach. The contemporary focus by this human activity, highlighted as essential and discriminative of psychic development, pressed a variety of scientific programs for the development of methods for accessing creativity.

But where is the operability of creativity in psychic systems? Can we observe creation? Is creation possible? What are the difficulties and limits, raised here? This research focuses directly on the question of the access to creativity and the emergence of creation. Our approach will have as starting point the psychic system based on the binary schema creativitylcreation, investigated through the Laws of Form by George Spencer-Brown and the systems theory of Niklas Luhmann, in a clear attempt to create an impossibility on the indication of creation, and the exploration of its contrast with proposals that feature, in a psychologist context, "creativity" as teleological, intersubjective, representative, compositional and progressive.

Keywords: creativity, creation, psychic system, Laws of Form, Systems Theory. 


\section{0. "Criando" um ensaio sobre criatividade...}

Se somos levados a criar um ensaio cuja temática é a criatividade, teremos de produzir algo "novo" que não existia antes de o produzirmos. Para isso, somos confrontados, com o facto de desenhar e produzir um certo objecto que não teria existência antes de um certo tipo de processo de mobilização e produção, cuja existência apenas se pode colocar após o facto inaugural da sua própria expressão enquanto objecto unitário em retrocesso.

Contudo, isto coloca a questão de sabermos se o predicado "novo" (que comummente é utilizado na comunicação quotidiana como correspondendo aos predicados "criativo", "inovador", "original", cada um deles aliado a expressões comunicativas num universo determinado, tal como por exemplo, a comunicação de carácter económico) se anexa necessariamente a algo cuja produção se poderia contrapor apenas e tão só à unidade da sua existência. Isto é, à diferença entre um objecto industrialmente produzido e um objecto criativamente produzido.

Não passará despercebido, através da descrição circular nos parágrafos acima, que estamos no campo de uma "metacriação"1, em relação às condições de produção e de aparecimento da criação deste ensaio. A verdade é que esta mesma situação fornece as condições de possibilidade da discussão, enquanto simultaneamente criamos este ensaio através das suas próprias possibilidades.

É engraçado como este aparente paradoxo - escrever sobre a criatividade criando algo na qual seja passível descrever o processo criativo -, tenta dar um passo atrás no próprio acto de criação. Esta observação de segunda-ordem pode ter como consequência a atribuição de um novo ponto de observação constituindo-se como um espaço de descrição da criação, colocando-o fora do processo criativo. Este movimento implica em si um processo de auto-descrição, de auto-referência, atribuindo o primeiro momento como "criativo".

Ora, se é verdade que uma pessoa pode indicar numa observação uma propriedade sobre o facto de se ser criativo, isto é, identificar nessa observação determinados indicadores que servem como constituin-

\footnotetext{
${ }^{1}$ Este termo aparece para nomear aquilo que é "o aparente processo paradoxal de definir criatividade, criando definições" (Rob Pope, Creativity: Theory, History, Practice, New York, Routledge, 2005, p.35).
} 
tes de um processo criativo, esta marcação exibe um domínio fora do espaço que não está marcado do espaço da criatividade, e que a constitui no seu surgimento.

\section{1. "Desenha uma forma!"}

Para podermos descrever esta dinâmica da observação de segunda-ordem, é necessário familiarizarmo-nos com certas ferramentas analíticas.

Uma dessas ferramentas, que iremos utilizar no desenho deste ensaio, é o conceito de forma de G. Spencer-Brown ${ }^{2}$, baseada no seu livro Leis da Forma. Aqui, Spencer-Brown descreve como é possível um cálculo matemático baseado na "forma" em que se desenha uma distinção no espaço para indicar um dos lados. Esta distinção cria um espaço marcado, o interior da distinção indicada, e um espaço não-marcado, o exterior da distinção. Esta operação permite a observação do interior da distinção indicada pela marca ${ }^{3}$ que nos permite tomar dois lados de uma distinção através da indicação de um dos lados e uma fronteira. A marca pode ser vista como o observador que faz a distinção. Estabelecer uma forma é distinguir, e "distinguir é uma operação, que como qualquer outra operação, requer tempo"4. Neste sentido, ambos os lados de uma forma são tomados juntos com a operação, separando os lados e trazendo para a frente o espaço na qual isto ocorre ${ }^{5}$.

Como, a par do movimento de cálculo enquanto forma, se recorre, também, ao conceito de sistemas psíquicos, deve entender-se o seguinte: que os sistemas psíquicos são sistemas que processam complexidade sob a forma de sentido (tal como os sistemas sociais). Estas formas têm consequências para as relações dos sistemas psíquicos (e sociais) na relação entre sistema e ambiente, sendo, de alta importância para

${ }^{2}$ George Spencer-Brown, Laws of Form, New York, Crown Publishers, 1972.

${ }^{3}$ George Spencer-Brown, Laws of..., cit., p. 4.

${ }^{4}$ Niklas Luhmann, "The Paradox of Form”, in Dirk Baecker (ed.), Problems of Form, Stanford, Stanford University Press, 1999, p.16.

${ }^{5}$ Dirk BAECKER, "A Calculus for Autopoiesis" (Junho 1, 2012), in Dirk Baecker \& Birger P. Priddat (eds.), Ökonomie der Werte: Festschrift zum 65. Geburtstag von Michael Hutter, Marburg, Metropolis, 2013, 249-267. (Disponível em SSRN: http://ssrn.com/abstract=2073362, consultado em 2012.04.12), p.3. 
estes sistemas como sistemas autopoiéticos (auto-reprodutivos), na medida em que, no caso de sistemas que são sistemas observadores, o observador tem de "focar nas distinções auto-determinantes e auto-determinadoras que um sistema utiliza para enquadrar as suas próprias observações"6.

De certa maneira, o sentido é "a unidade de actualização e virtualização, ou re-actualização e re-virtualização, como um processo auto-propulsor (que pode ser condicionado pelos sistemas)" ", e para descrever estas operações no âmbito das noções que nos oferece Spencer-Brown, teremos de as transpor, utilizando as noções semânticas que servem, dalgum modo, de correspondentes às noções de apresentadas no Leis da Forma, correspondendo "diferença" à "distinção" e "identidade" à "indicação". "A diferença entre diferença e identidade é instituída, por assim dizer, através da diferença entre actualidade e potencialidade, para controlar a última dentro das operações da primeira" ${ }^{\text {. Por }}$ outras palavras, a indicação de uma actualidade não elimina aquilo que não é actualizado, mas desloca-as para um estado de não-actualização, onde podem ser "preservadas" como virtualidades dentro de um certo horizonte da distinção. Iremos ver como isto ocorre no âmbito da criatividade mais à frente.

Pode-se pensar que a forma é a fronteira que delimita a indicação que está a ser usada do resto do espaço não-marcado. Todavia esta leitura delimitaria o próprio surgimento da forma. Nesse sentido, temos de ter em atenção que a forma não é só a fronteira, mas também contém os dois lados que separa. Esses dois lados não participam no desenho da forma de maneira igual. O uso operacional da forma só pode proceder de um dos lados. O que é distinguido, tem de ser distinguido da distinção ela própria em ordem a ser operacional.

Mas quando e onde começa a distinção? Aparentemente do nada e em nenhum ponto específico no tempo ${ }^{9}$, muito embora elabore em si,

${ }^{6}$ Niklas Luhmann, "Deconstruction as Second-Order Observing", New Literary History, 24 (1993), pp.763-782, p.767.

${ }^{7}$ Niklas Luhmann, Social Systems, Stanford, Stanford University Press, 1995, p.65.

${ }^{8}$ Niklas Luhmann, Social..., cit., p. 66.

${ }^{9}$ Cf., DiRk BAECKer, "A Calculus for..., cit., p. 3, e Niklas Luhmann, "The Paradox..., cit., p. 16. 
como vimos, uma fronteira e tempo através da sua operacionalidade. $\mathrm{Na}$ medida em que o resultado da distinção tem de funcionar como unidade, a distinção não pode ser designada nem nomeada, ela apenas está lá. Este facto aparece-nos através da injunção "Desenha uma distinção"! ${ }^{10}$. Sem esta injunção o espaço permanecerá vazio e indiferenciado.

Por outro lado, se obedecermos à injunção "desenha uma forma", a forma desenhada no espaço vazio contempla uma indicação e uma fronteira entre o lado interior e o lado exterior. O desenho implica temporalidade, apresentados enquanto a indicação e delimitação do espaço marcado e não-marcado. Essas operações têm de ser executadas sequencialmente, como um processo. Ora, a distinção só é uma distinção se providenciar ambos os lados simultaneamente, mas a operacionalidade da forma, que indicando o interior, corta um lado externo que permite a distinção do interior em contraposição. Esse cruzamento, que assume a execução da operação de re-entrada (neste caso: da re-entrada na forma da distinção da indicação e distinção), só pode ser executado sequencialmente. Neste sentido, "a forma é simultaneidade da sequencialidade" 11 .

Estas duas respostas, à pergunta acima colocada, anunciam um conjunto de paradoxos elaborados através de um pensamento da forma, que serão a base do resto da nossa criação ensaística. Ora, numa interpretação clássica lógica, o paradoxo é algo que deve ser evitado, mas ao ser encontrado, ele marca o lugar onde, na formulação determinativa da lógica clássica e formal, se pretende desdobrá-lo, isto é, pretende substituir os lados do paradoxo por identidades estáveis, em ordem a indicar quais os possíveis e diferentes níveis de cálculo ou, por outro lado, de evidenciar um erro na sua formulação.

É neste enquadramento, aonde podemos associar a pressão contemporânea que a comunicação colocou na variância semântica do conceito "criatividade" (provocando, no nosso entender, uma concepção errada e pouco produtiva em relação à sua própria génese criativa, incluída tradicionalmente no acto de fazer algo novo), esquecendo que esta indicação surgiria com uma não-criatividade simultânea. Assim, a indicação da criatividade, enquanto distinção, abre o espaço não-marcado por

${ }^{10}$ George Spencer-Brown, Laws of..., cit., p. 3.

${ }^{11}$ Niklas Luhmann, "The Paradox..., cit., p. 19. 
essa distinção como aquilo que é não-criativo, ou mais precisamente, a não-criatividade, e precisamente por isso elabora algo como "criativo".

Por outro lado, o espaço não-marcado da indicação da criatividade pode ainda ser mais peculiar. Se cruzarmos a fronteira da criatividade podemos encontrar o seu oposto, não apenas na negação da indicação (na sua abrangência), mas também, e necessariamente, a abertura de uma indicação que corta o espaço não-marcado na medida de uma unidade da distinção. Esta utilização daquilo que Spencer-Brown chama de "forma de cancelamento" (form of cancellation).

Com estas ferramentas, que irão funcionar como elementos na criação deste ensaio, podemos elaborar três momentos que nos irão ajudar a providenciar substrato para este texto: num primeiro momento, iremos explicitar o conceito de "criatividade" como pilar comunicativo contemporâneo e seu efeito na temática de estudo sobre o sistema psíquico enquanto objecto e a sua genealogia. Num segundo momento, a caracterização dos espaços de criatividade, caracterizados como "estados não-criatividade" e o "estados criatividade". E num terceiro momento, a exploração da ideia de que a criatividade permanece ligada e pode ser contrastada inexoravelmente com a noção de criação, baseada num contexto de carácter poiético com conotações místico-religiosas, e não apenas num contexto descritivo.

\section{Uma genealogia da "criatividade"}

Chegamos até aqui sem definir especificamente o que é "criatividade". Ainda assim conseguimos produzir o seu próprio discurso, isto é, uma certa tematização. O que demonstra que herdámos uma concepção dela, enquadrada por uma certa transmissão a ela relacionada. Ora, quando uma pessoa se propõe a escrever um ensaio sobre "criatividade", à partida tem de distinguir aquilo que é criatividade da não-criatividade. Este movimento de distinção está dado à partida e funciona como substrato dele próprio. Não aparece, portanto, como surpreendente que essa distinção seja produto de, por um lado, a totalidade da história que pode ser encapsulada através do epítome "criatividade", como, por outro lado, da necessidade que uma pessoa tem, enquanto produtor, de observar a distinção mediante o seu próprio substrato, contemplando para já a sua temporalidade. 
Este duplo movimento coloca-nos num ponto pivotal entre uma recepção da temática da "criatividade", e entre uma dimensão observacional de segunda-ordem dentro da capacidade finita de observar os próprios enviesamentos desta história ${ }^{12}$. Por isso, logo à partida, da maneira como desenhámos este ensaio este não poderia estar alheado a uma certa utilização comunicativa e accional da temática da criatividade.

Assim, podemos observar que não é aleatório que esta noção se tenha apresentado como um tema de grande importância para a sociedade contemporânea, nomeadamente no contexto da comunicação económica e social. Termos como "criar", "inovação", "performance", "empreendedorismo", "design" (entendido nesta nuance semântica), "produtividade", e termos correlativos tais como "mudança", "novo", "original", "inovador", "criativo", permeiam as conversas quotidianas, os discursos publicitários, económico-empresariais, científicos e os discursos susceptíveis de alcance político e pedagógico.

É, precisamente, no contexto do pensamento económico que podemos indicar o interesse contemporâneo da comunicação por este tema, sendo que podemos traçar a génese de tal interesse na clara articulação entre as noções da "criatividade" e do "capitalismo" feita por Joseph Shumpeter, no Capitalism, Socialism and Democracy (1942). Shumpeter coloca o capitalismo por natureza como "uma forma ou método de mudança económica" e que este nunca pode estar estacionário ${ }^{13}$. O seu motor, que o "impulsiona" e o "mantém em movimento", "vem dos novos bens de consumo, de novos métodos de produção ou transporte, de novos mercados, de novas formas de organização industrial que o empreendimento capitalista cria" $^{14}$. Focando neste tipo de objectivo do meio de produção, podemos identificar criatividade como aquilo que empreendedores mostram quando introduzem "coisas novas" no mercado, sendo que é esta actividade (num contexto de uma "criatividade destrutiva") que os fazem ser agentes privilegiados da mudança. É este processo de inovação que permite o progresso no mundo, como

12 Alf Rehn \& Christian de Cock, "Deconstructing Creativity", in Tudor Rickards, Mark A. Runco, \& Susan Moger (eds.), The Routledge Companion to Creativity, New York, Routledge, 2009, pp.222-232.

13 Joseph Shumpeter, Capitalism, Socialism and Democracy, (1942), New York, Routledge, 2003, p.82.

${ }^{14}$ Joseph Shumpeter, Capitalism, Socialism ..., cit., p.83. Sublinhado nosso. 
exemplificado pela expansão e entrelaçamento dos campos da tecnologia e economia.

Contudo não podemos esquecer, no seu cerne histórico, a discussão sobre o que significa a criatividade que, de certa maneira, tinha estado incluída no campo das teorizações da arte, e circunscrita ao artista, muito antes desta "utilização" económica da criatividade.

Ora, podemos verificar que o conceito de "criatividade" sofreu um conjunto considerável de variações semânticas. No período da Grécia Clássica "criar" implicava uma sujeição a regras, com a excepção da poética. Estas regras provinham da imitação de algo, da natureza e das suas formas, conjugando cânones determinados para cada techné. Na Roma Antiga, o conceito foi expandido, na medida em que a inspiração e a imaginação eram a base dos artistas visuais e poetas.

No cristianismo medieval a palavra, em latim, creatio aplicava-se unicamente a Deus, na célebre designação do acto de Deus de "creatio ex nihilo". Perante este contexto na Idade Media só Deus podia criar e todas as artes por consequência eram meramente tecnhé, ofícios com regras, e não tinham nada a ver com criatividade. A resistência da adopção da palavra criatividade em relação ao ser humano, muito teve a dever à noção de que o ser humano não poderia criar algo de nada, ex nihilo, e que esta função estava determinada a Deus. Com a evolução da sociedade, no início do período moderno, o poeta polaco Maciej Kazimierz Sarbiewski no séc. XVII utilizou a designação criatividade na actividade humana, mas ainda aplicando-a apenas à poesia ${ }^{15}$. De qualquer modo, o conceito progrediu e é no séc. XIX que se assume definitivamente no campo disciplinar da arte, que monopoliza essa mesma característica. No séc. XX o conceito de criatividade passou a ser utilizado nos campos da ciência, e, depois, na economia e restantes áreas disciplinares. Esta transferência de conceitos próprios da área disciplinar da arte para outras áreas, abriu o caminho à indicação de que a criatividade poderia ser algo de carácter não-excepcional, mas ao mesmo tempo não-trivial.

É, neste contexto, que vemos a criatividade como conceito operativo a deslocar-se do domínio onde estava confinada, o domínio comu-

${ }^{15}$ Cf., WŁadysŁaw Tatarkiewicz, A History of Six Ideas: an Essay in Aesthetics, The Hague, Martinus Nijhoff, 1980, p. 71. 
nicativo da arte, para domínios mais transversais na cultura humana. Aquilo que era reservado ao artista, no meio da sua produtividade enquanto génio criador (forma pela qual no séc. XIX se codificou a variância das produções artísticas e a sua diferenciação a outros tipos de produção) na medida em que apenas indivíduos com uma determinada "sensibilidade" podiam dispor dos grandes movimentos inconscientes e trazê-los à luz para uma fruição do meio social, passou a infiltrar-se, por exemplo, nas chamadas "ciências matemáticas"16, e não só, nos finais do séc. XIX e inícios do séc. XX.

A verdade é que com o advento da teoria da evolução como teoria de adaptação natural, e na sua relação com a criatividade da vida em relação ao seu meio ambiente, tomou-se por garantido a intersecção dos conceitos de criatividade enquanto orientada para o sistema psíquico em correlação com o sistema orgânico e o sistema das leis naturais. Como se assumiu, também, como fundamental a associação da criatividade em relação à própria sobrevivência dos seres vivos, e mais mormente ao surgimento e sobrevivência da psique (da mente). Esta aproximação, aliada à visão antropológica marxista onde a criatividade se pressupunha num contexto do ser humano enquanto produtor, sendo que esta produção se desenvolveria na transformação de processos naturais, onde o trabalho seria essa actividade criadora, produziria a proposta de que o ser humano cria tanto o seu mundo como a si próprio.

Isto criou, por assim dizer, uma textura ideológica que, aliada a uma determinada leitura da teoria da evolução e da ideia de progresso do Iluminismo (de mudança como correlato significativo da criatividade da evolução, fosse em sistemas vivos fosse em sistemas psíquicos), com a produtividade do ser humano como trabalhador e transformador do mundo e de si próprio, justificou um determinado tipo de exigência sobre a necessidade de se ser criativo. Esta textura comunicativa pode ser esquematizada através do binário operativo velho-mau/novo-bom ${ }^{17}$,

${ }^{16}$ A título de exemplo, veja-se o ensaio sobre a criatividade na actividade da matemática de Jules Henri Poincaré, "Mathematical Creation", originalmente publicado em 1908, reimpresso por várias vezes, nomeadamente: in Brewster Ghiselin (ed.), The Creative Process - A Symposium, Los Angeles, Cambridge University Press, 1954, pp. 22-31.

${ }^{17}$ Alf Rehn \& Christian de Cock, "Deconstructing ..., cit., p.224. 
correlacionados com os binários conservador/liberal num sentido político, e no sentido psicológico com o binário determinação/liberdade.

Em suma, propondo a criatividade como motor e movimento da sobrevivência de um certo modo de produção, cujo progresso consiste na crescente acumulação de objectos criativos e no controlo sobre esta geração do criativo, promove um programa político-económico que pretende conhecer, dominar e articular o conjunto de propriedades que promovem, instilam e propagandeiam um determinado tipo de actividade que seja criativa. Este programa, com a emancipação das disciplinas experimentais neuro-psicológicas, abriu espaço para a tentativa de entender e analisar a criatividade num dos centros da sua génese: a psique.

\section{A noção de "criatividade" em contexto psicológico}

Ora, o foco por esta actividade humana, realçada como essencial para o desenvolvimento humano e económico, permitiu uma diversidade de produções e estudos científicos de forma a fomentar a criatividade, numa época em que essa nova capacidade pode, presumivelmente, diferenciar as velhas economias (baseadas na escassez dos recursos e a sua procura, utilizando esta escassez como medida para a valorização desse mesmo recurso), das novas economias (baseadas numa diferenciação e capacidade de conceber o novo, sendo essa diferenciação a medida do seu valor).

Estes estudos e produções obtiveram uma fixação num carácter pragmático na medida em que o seu objectivo seria o ensinar técnicas criativas práticas acessíveis a qualquer agente disponível a ser criativo e inovador. Desde o "brainstorming" de Alex Osborn, ao modelo "Teoria da Solução Inventiva de Problemas" (modelo TRIZ) de Genrikh Altshuller, ao "pensamento lateral" de Edward de Bono, passando pelos "mapas mentais" de Tony Buzan, às "method cards" da empresa de design IDEO, entre muitos outros materiais, modelos, grelhas e técnicas passo-a-passo, orientadas tanto para ambientes de gestão empresarial, através de centros de investigação research \& development, como na sua utilização quotidiana.

Esta contextura contribui para o nascimento da chamada, popularmente, indústria da "auto-ajuda", ou por outras palavras, para o grande 
desenvolvimento contemporâneo da indústria do "desenvolvimento pessoal". Herdando também considerandos de carácter psicanalítico, a pessoa passou a ter uma dimensão em que é relegada para um plano de "mau", velhos hábitos e rotinas, que estejam em contraste claro com o "bom" e "novo", que é ao mesmo tempo desejado e uma indicação do que realmente a pessoa "é lá dentro". Este campo foi assumido pela disciplina da Psicologia de forma directa, na qual foi desenvolvida uma proposta de carácter desenvolvimentista, sendo nesse caso a mais popular, a proposta da "hierarquia das necessidades" e a correspondente "auto-actualização" de Abraham Maslow ${ }^{18}$.

\subsection{Psicologismo e os pilares da "criatividade"}

O foco da Psicologia na questão da criatividade pressionou uma sistematização do sistema psíquico, na medida a aceder aos parâmetros dos meios de produção da criatividade e da reprodução desses meios.

A importância do acesso à criatividade é capital para entendermos as investigações contemporâneas da psicologia. Isto porque, se realmente observarmos o meio onde essas comunicações se reproduzem, temos de dar conta de um determinado tipo de ambiente, uma atmosfera, que se caracteriza pela sua capacidade de informar estados produtivos da comunicação/acção, e de funcionar como superestrutura, de onde emana temáticas gerais para a mesma reprodução dessas observações. Esta ambiência, se assim se puder caracterizar, funciona de facto como uma determinada ideologia, guiadora e reguladora, no background, das próprias noções que acompanham a necessidade de, neste caso, se comunicar e observar a criatividade.

A título exemplificativo, a necessidade que uma pessoa tem de criar este artigo utilizando a "minha própria criatividade", permanece refém destes tipos de pressões comunicativo-ideológicos, que, agregadas, iremos chamar de psicologismo. O psicologismo aqui não pode ser entendido apenas como a doutrina que reduz operações abstractas e psíquicas

${ }^{18}$ Abraham Maslow, "A Theory of Human Motivation” (1943), in Psychological Review, 50, 370-396. (Disponível em Classics in the History of Psychology: http://psychclassics.yorku.ca/Maslow/motivation.htm, consultado em 2011.11.24), [p.382]. 
a operações de base empírica, natural ou social, abundantemente criticada por filósofos como Frege e Husserl, entre outros. Mas a algo ainda muito mais entranhado no pensamento actual capaz de dirigir e actualizar formas de comunicação e de acção tanto em subsistemas comunicacionais como a Psicologia, a Neurologia, Educação, Direito, e a Arte, e também, naquilo que o sistema psíquico, entendido como sistema acoplado a estas estruturas, se observa reflexivamente e como se determina nas actualizações verdadeiramente oferecidas por esse mesmo sistema de possibilidades. O psicologismo surge aqui, como uma pressão ideologicamente generalizada que interpela a estrutura base na reprodução dos seus modos de produção de certas formas de experiência. Assim, entendemos psicologismo como ideologia, da qual parte a diferença e conjunção daquilo a que mais basicamente se insere a disciplina regional da Psicologia, mas não só.

A caracterização da ideologia do psicologismo parte de uma leitura de uma herança bicéfala que caracterizamos, por um lado, através das codificações sobre a investigação da referencialidade do sinal "Eu" (orientada sob a pergunta “Quem sou eu?"), sendo que a estrutura dessa referencialidade constrói determinadas funções, que assumem uma certa herança e tradição relacionáveis com aspectos de correspondência e privilégio a uma estrutura referencial clássica e as suas modelações realistas, desembocando na disciplina da Psicologia, de carácter geral, como um dos expoentes regionais. E por outro lado, naquilo que consideramos ser a "temática da anomalia", emancipado nos desenvolvimentos helénicos encontrados no Corpus Hipocrático. Esta tematização, com orientação naturalista, é direccionada para a codificação da saúde e doença na sua metodologia de entender os signos no corpo humano como fenómenos sintomáticos causados por uma enfermidade, obtendo a mais profunda, e de algum modo, oculta influencia no pensamento filosófico e psicológico. É aqui que é codificada a caracterização de doença como o que está oculto (o que não se manifesta clara e distintamente), e os sinais (que são uma manifestação observável e natural da patologia), mas remetentes, apenas veículos para um outro lugar que permanece oculto e enfermo, mas realmente verdadeiro e causador da aparência.

Estruturalmente, podemos caracterizar esta ideologia da seguinte maneira: Primeiro, o sistema psíquico é interno, central e oculto, e por isso mesmo, fonte inesgotável de surpresas, por outras palavras, não 
confiável. Assim sendo, é necessário conhecer esta fonte de forma a procedermos à sua compreensão geral. Segundo, neste ímpeto, a estrutura psíquica pode ser reduzida a certos signos que correspondem a estados. Por outras palavras, o signo corresponde a algo que se passa internamente no sistema psíquico caracterizado acima. Terceira, através da teoria referencialista clássica, é adoptada à gramática subsequente de carácter categorial e lógico, sendo o seu principal mecanismo o modus ponens.

Neste contexto, os signos exprimem algo, sendo eles próprios de valor residual em relação àquilo que apontam. Os signos são representações do mundo (interno ou externo) e, entendidos como sintomas, são precisamente falíveis, e sujeitos a erro ou ilusão, na medida em que o signo, enquanto unidade estrutural, através da sua combinatória, devem espelhar uma certa ordem, que se pressupõe esteja contida nessa realidade. Esta estrutura da significação aqui caracterizada apenas pode representar, isto é, corresponder a algo que está na realidade. $\mathrm{O}$ oculto é assim pressuposto com uma certa organização, apenas acessível através do signo mediado por uma certa gramaticalidade. E quanto mais representativo for esse signo, melhor será o seu diagnóstico e previsão.

Este tipo de entendimento origina que determinadas frases como "Eu sinto que...", "Eu creio que...", "Eu desejo que...,, etc., designem algo que seja uma identificação desse eu com um estado que é identificável por si próprio como sendo de determinada maneira orientada para um certo objecto. É esta preocupação com a mimesis, de expressar "o que me vai na alma", que é orientadora deste paradigma. $\mathrm{O}$ "eu exprimo as minhas emoções" como acontece muitas vezes numa descrição artística feita pelo músico ingénuo, na medida em que o Eu identifica um estado, neste caso emocional ou vários estados emocionais, e a partir daí (ex)prime através de um signo, de uma narrativa de uma composição que é referencializado de volta, isto é, provoca auto-referência, na sua identificação real.

Esta identificação realiza-se, normalmente, por um nexo significativo de extrema importância quando se utiliza o pronome "Eu" que o delimita para um referencial-real de forma ostensiva. Dependendo se privilegiamos o estatuto ou não desta auto-referência, a verdade é que ficamos com a sensação de que exibe maior força esta utilização através de mim próprio da palavra "Eu" ou suas combinações sígnicas. Contudo, esta identificação pessoal entra em conflito com a interpretação de 
um observador externo e sua grelha de leitura. É este conflito que providencia uma caracterização do eu como patológico, providenciando assim uma forma observacional e despegada, de relatarmos o que os outros "eus" comunicam e agem.

\subsubsection{Alguns dos nexos remissivos da psicologia contemporânea acerca da criatividade}

Na psicologia contemporânea a criatividade oscila entre dois aspectos: a criatividade como aspecto fisio-genético, (por exemplo, o génio); e a criatividade como uma faculdade da mente. Ambas incluem um conjunto de registos de investigações empíricas.

\subsubsection{Criatividade em estruturas fisiológicas}

A indicação de identidade do signo "Eu" a estruturas físicas levanta a indicação de uma camada signitiva ser remetida para uma estrutura fisiológica que, elevando o estatuto empírico do cérebro e/ou sistema nervoso como locus e foco central da actividade de cognição e, por conseguinte, da criatividade, levou ao desenvolvimento de modelos baseados na ideia de que a criatividade requer a coactivação e comunicação entre regiões do cérebro que normalmente não são muito "utilizadas"19, desembocando em dois modelos gerais ${ }^{20}$ : por um lado, na lateralização das funções do cérebro ${ }^{21}$, isto é, numa divisão estrutural entre hemisfério-esquerdo e direito cada um correspondendo a um certo carácter do pensamento (atribuindo à secção esquerda uma dimensão lógica e à

${ }^{19}$ Kenneth M. Heilman, Stephen E. Nadeau \& David O. Beversdorf, “Creative Innovation: Possible Brain Mechanisms”, Neurocase, Vol. 9, No. 5, 2003, pp. 369-379.

${ }^{20}$ Allison B. Kaufman, Sergey A. Kornilov, Adam S. Bristol, Mei Tan, \& Elena L. Grigorenko, "The Neurobiological Foundation of Creative Cognition", in James C. Kaufman \& Robert J. Sternberg (Eds.), The Cambridge Handbook of Creativity, New York, Cambridge University Press, 2010, p. 217.

${ }^{21}$ Ned Herrmann, "Is it true that creativity resides in the right hemisphere of the brain?", Scientific American, Janeiro 26, 1998, (http://www.scientificamerican . com/article.cfm?id=is-it-true-that-creativit, consultado em 2013.05.12). 
direita uma dimensão "criativa" 22 ); e por outro, na ideia de que a criatividade é derivada da redução na inibição da rede neuronal, que é originada no lóbulo frontal. Um exemplo deste modelo podemos encontrar nas investigações de Larry Vandervert ${ }^{23}$ que tenta descrever como o lóbulo frontal e as funções criativas do cerebelo colaboram na produção da criatividade e inovação, através das associações e dissociações de memórias de trabalho (working memory) pré-alimentadas (feedforward) para o córtex pré-frontal.

\subsubsection{Resolução de problemas e racionalidade prática}

No outro aspecto, a objectificação das psico-logias em módulos da racionalidade humana, transformou a investigação empírica em investigação sobre contentores determinados de certas propriedades anteriormente reconhecidas das faculdades da psique (ainda que sem saber como aconteceu esse reconhecimento). Contentores como "motivação", "cognição" e "emoção ${ }^{24}$, "linguagem" 25 , "comunicação" e "persuasão" 26 , entre muitos outros, nas quais a "criatividade", têm vindo a ser um módulo de investigação psicológica. Não só dentro de um enquadramento, como vimos na secção acima, da identificação no

${ }^{22}$ Amplificadas pela literatura dentro do género da "psicologia popular", por exemplo, Betty Edwards, Drawing on the Right Side of the Brain: The Definitive, London, Tarche, 2012.

${ }^{23}$ LARRY VANDERVERT, "How working memory and cognitive modeling functions of the cerebellum contribute to discoveries in mathematics", New Ideas in Psychology, Volume 21, Issue 2, August 2003, Pp. 159-175. (http://www.sciencedirect.com/science/article/pii/S0732118X03000126, consultado em 2013.08.02). No nosso ponto de vista, a versão de Vandervert é muito semelhante aos exercícios de visualização de atletas olímpicos, e também muito similar a uma fundamentação daquilo que são alguns exercícios terapêuticos da Programação Neurolinguística de R. Bandler e J. Grinder.

${ }^{24}$ Cf., David Yun Dai \& Robert J. Sternberg (eds.), Motivation, Emotion, and Cognition: Integrative Perspectives on Intellectual Functioning and Development, New Jersey, Lawrence Erlbaum Associates Publishers, 2008.

${ }^{25}$ Cf., E. Spinelli \& L. Ferrand, Psicologia da Linguagem. Lisboa, Instituto Piaget, 2009.

${ }^{26}$ Cf., C. Chabrol, \& M. Radu, Psicologia da Comunicação e Persuasão Teorias e Aplicações, Lisboa, Instituto Piaget, 2008. 
sistema nervoso e suas operações nos mecanismos electro-fisiológicos, mas numa perspectiva cognitiva que permite a elaboração e sistematização de elementos causais responsáveis pelo estado psíquico "criativo".

Estas investigações assumem como pressuposição o paradigma de que o sistema psíquico é um sistema cognitivo e que este tem uma funcionalidade evolutiva dentro do âmbito da resolução de problemas. A racionalidade assim descrita é estudada neste âmbito como os esquemas de racionalidade prática passíveis de resolver de maneira inovadora um certo problema proposto ${ }^{27}$. Maior criatividade a solução do problema terá, se obedecer ao rácio: mínimo de tempo com os componentes ou objectos do ambiente circundante (ilustrados caricaturalmente pela série de televisão MacGyver), na construção da solução do mesmo. Este método também permite um certo tipo de operação de medição da criatividade, a par da medição da inteligência, na categorização e classificação das pessoas criativas. ${ }^{28}$

É claro que não esgotamos aqui todas as vertentes produtivas cuja situação empírica implica uma investigação "laboratorial" desta faculdade. Contudo, quando elaboramos uma pergunta guiadora de uma investigação deste tipo, como por exemplo, "que elementos estarão em jogo na minha consciência para permitirem criatividade?", não podemos senão observar os seus pressupostos enquanto essa pergunta surge. Aliás, o enquadramento da mesma como "faculdade", como se fosse possível sequer abstrair, ou destilar, de um conjunto complexo de operações, aquilo que intrinsecamente ao sistema é a operação da criatividade, reduz e confunde o potencial de observar distinções que foram feitas à partida para essa própria observação.

Fazendo uma observação de segunda-ordem, teríamos sempre de perguntar como e porquê a distinção da criatividade em relação a outros aspectos da vida psíquica, e como descriminá-los. Neste ponto estaríamos a observar as observações e as modelações produzidas por essas

${ }^{27}$ Podemos observar este contexto, por exemplo, na iniciativa "Problemistics: The Art and Craft of Problem Dealing - Courseware on Problem Finding and Problem Solving", (http://www.problemistics.org/courseware/front.page.html, consultado em: 2013.08.21).

${ }^{28}$ Vejamos o programa (ideológico) proposto pelo estudo de Kimberly Seltzer \& Tom Bentley, Creative Age - Knowledge and Skills for the New Economy, London, Demos, (http://www.culturenet.cz/res/data/004/000574.pdf, consultado em: 2013.09.03). 
mesmas distinções. Este é um trabalho a ser feito, mas não nos compete aqui em tão curto espaço de tempo fazê-lo.

O objectivo desta secção é a indicação dos pressupostos psicológicos envolvendo a tematização da criatividade. Se não entendermos as modelações que o psicologismo impõe na sociedade contemporânea, permanece a operacionalidade dentro das distinções (que enumerámos acima) do psicologismo sem nunca cruzarem a fronteira. Mantendo esse domínio a única coisa que permanece é a luta pelo acesso ao próprio sistema psíquico, a luta pelo acesso à criatividade na sociedade contemporânea. Essa luta contemporânea de consequências político-económicas impõe descriminações ao nível social: "empreendedores mais criativos do que funcionários", "artistas mais criativos do que trabalhadores", "crianças (ou os "mais novos") mais criativos do que os idosos", etc. Por outras palavras, a criatividade instalou-se como categoria conceptual de dominância em relação a outros conceitos, e este "mais que" exibe a operacionalidade dessa conectividade. Pretender ser criativo promove na hierarquia do status social e/ou empresarial, isto é, promove maior grau conectividade nas estruturas sociais assim impostas.

De certo modo a tematização da observação da criatividade aparece enquadrada num conjunto de critérios, de distinções, que são essenciais para a sua observação. Iremos em grosso modo passar os olhos por alguns desses critérios. Relembramos que nesta tematização, todas estas distinções são enquadradas pelo psicologismo dominante. Por isso, vejamos que elementos são pressupostos no funcionamento daquilo que descrevemos nas duas secções acima ${ }^{29}$ (chamamos à atenção que esta é uma simplificação de um certo e determinado conjunto de características, e não nos esquecemos que a nossa observação é limitada na sua própria observação, muitos outros elementos podem ser construídos):

(i) A criatividade aparece codificada como teleológica. Isto é,é articulada de acordo a um objectivo ou objecto que seja criativo/novo/inovador/etc., ou que seja problemático/bloqueador/antiquado/etc. Toda a temática da criatividade, como criadora de soluções para problemas, enquadra-a no âmbito do objecto "problema". Este problema tem a característica de não proporcionar conectividade no sistema, e por isso

${ }^{29}$ Estas características não têm nenhuma ordenação hierárquica entre si. A numeração apenas exibe o arranjo linear da mesma. 
o enfrentamento do mesmo prevê a sua solução, e a elaboração de processos e métodos para o resolver.

(ii) A criatividade aparece na dimensão da intersubjectividade. Como vimos através do psicologismo, a colocação de, por um lado, sujeitos e, por outro, a comunicação enquanto transmissor de mensagens, estabelecem o fundamento para a criatividade, ou o seu objecto, como partindo de um sujeito, ou de vários sujeitos que em organização empresarial ou comunitária (técnicas como o brainstorming aparecem como característico dessa dimensão) comunicam, expressam, as suas ideias.

(iii) A segunda característica, acima apresentada, está conectada com a dimensão da representatividade. A teoria da representação como mimesis de um dos lados da distinção posiciona a noção da descrição de estados que na sua representação "expressam" o seu "interior" ou "exterior". Assim, o que aparece como objecto da criatividade é a "objectificação exterior para outros (ou possivelmente para si próprio)" ${ }^{30}$ de algo interior que é expressável.

(iv) Uma outra característica da criatividade aparece sob a forma da sua particularidade composicional e progressiva. No ponto de vista composicional a operacionalidade da criatividade é vista como sequencial e aditiva, isto é, através de um conjunto de procedimentos, ordenados de forma linear, providencia a produção de elementos cujo aglomerado evidencia certas propriedades de emergência do objecto criativo. Este composicionalismo é visto como progressivo, porque assume que a emergência de um composto mais complexo que agrega as partes, singulares e mais simples, como sinal do progresso, de evolução, se olharmos numa perspectiva biológica.

Ora, com este contexto, para nos podermos orientar na próxima parte do ensaio, iremos optar por contrastar a palavra "criatividade" (ainda que sendo de certo modo injustos para com ela) como estando no âmbito de uma leitura das características enunciadas acima, com a palavra "criação", enquanto operação na qual se pode observar a criatividade.

${ }^{30}$ Valentin Volosinov, Marxism and the Philosophy of Language, New York, Harvard University Press, 1973, p.84. Sublinhado no original. 


\section{3. "Criatividade" e "Criação"}

A "criatividade" é o termo que é assinalado para descrever objectos criativos na qual se exibe o conjunto de propriedades que enunciamos acima: teleológica, intersubjectiva, representativa, composicional e progressiva.

A nossa aproximação é que todos estes elementos são elementos necessários para a criatividade mas não são suficientes para a criação. Por outras palavras, se cruzarmos a fronteira da criatividade entraremos na distinção criatividadelcriação $0^{31}$.

Agora, se olharmos para esta distinção, e indicando a criatividade como o conjunto de características que organizámos, somos obrigados a distinguir, de forma mais produtiva para a nossa observação, como criaçãolcriatividade. Porquê esta inversão? Bem, porque se estamos a lidar com uma forma na maneira de apresentar a nossa observação, estamos automaticamente a fazer uma distinção anterior de operacionalidadelobservação. Temos consciência que, tal como aponta Luhmann ${ }^{32}$, para podermos desenhar esta distinção temos de ter a noção de que operação e observação têm de ser distinguidas, mesmo que fazendo esta distinção seja uma operação de observação, ou seja, um paradoxo. Assim, ao distinguirmos "criaçãolx" (sendo $x$ uma variável no espaço não-marcado) estamos a actualizar a distinção operacionalidadelobservação, permitindo-nos ter formas como criaçãolcriatividade, criaçãolnovo, criaçãoloriginal, criaçãolinovador, etc.

Mas vamos imaginar que fazemos uma operação de re-entrada da operacionalidadelobservação na distinção "criaçãolx". Aqui estaremos a introduzir o paradoxo da forma que explicitamos na secção 0: que iremos designá-lo como o paradoxo do espaço/tempo (simultaneidade da sequencialidade). O que surge é a singularidade do paradoxo no aparecimento do "nada" da criação.

${ }^{31}$ Utilizaremos a barra vertical (I) como notação (económica) para a representação figurativa da "forma". Outras notações existem, passando pela marca que Spencer-Brown utilizou originalmente (com um traço horizontal que representa a indicação e um traço vertical que representa a distinção), ou através de parênteses.

${ }^{32}$ Cf., Niklas Luhmann, “The Paradox..., cit., p.16. 
Estamos a entrar no terreno dos místicos e numa teologia de carácter de certo modo apofântico. Este terreno não é confortável para uma sociedade que guia muitas das suas observações num carácter fisicalista. Ora, a crítica dos fisicalistas é elaborada numa crítica quanto à possibilidade de "creatio ex nihilo", aproveitando a posição base dos filósofos naturalistas helénicos da Grécia Antiga, que exprimiram o princípio "do nada nada pode vir". Parece evidente esta crítica. De um ponto de vista físico o nada é um conceito que indica a ausência do físico, e numa contemporaneidade que observa o físico como um complexo energia-matéria, o "nada" significa "ausência de energia-matéria". Ora, parece óbvio que, se o que serve de base para a operacionalidade física se encontra ausente, $\operatorname{logo}$ não pode haver uma criação de novos objectos físicos.

Aceitamos esta argumentação. Contudo, não estamos a trabalhar na categoria de fisicalidade, que é apenas uma distinção de observação, mas sim num nível particular aos sistemas psíquicos e sociais: a categoria de sentido. Como se articula então o sentido com o nada?

Antes de respondermos em mais detalhe a esta pergunta, convém focarmo-nos na caracterização do sistema psíquico, pois é daqui que existe um dos lados da operacionalidadelobservação da criação.

\subsection{Sistema psíquico e o âmbito do sentido}

O sistema psíquico, como apresenta Luhmann, actualiza-se através, e tem as suas operações na consciência (em pensamentos) "na base de um nexo de estados conscientes unificados (auto-referenciais)" "33. Estes pensamentos actualizam-se na categoria geral do sentido, a mesma categoria que serve de base para os sistemas sociais. O sistema psíquico é sistema psíquico porque diferencia-se operacionalmente entre sistema psíquico e não-sistema psíquico (actualizando a operação entre sistema e meio). Esta distinção permite operar de acordo com a sua auto-referência sobre o nível de operação a que o sistema psíquico tem acesso e aquilo que podemos dizer que certos eventos que lhe acontecem. Esta distinção é a que conduz o sistema psíquico à referencialidade. Assim o sistema psíquico actualiza certas formas, na medida

${ }^{33}$ Niklas Luhmann, Social ..., cit., p.59. 
em que a possibilidade delas se encontra na virtualização ao redor da actualização da forma que utiliza. A distinção entre a potencialidade e actualidade descentra a sua operação onde não interessa tanto a actualização em si, como as possibilidades excedentes que pressionam essa mesma actualização.

Nesta descrição pode haver a ideia, muito comum na contemporaneidade, de que a diferença e a passagem de possibilidades a actualidades aparecem como um "processo ontológico" ${ }^{34}$, como realização da potencialidade à actualidade ${ }^{35}$, articulando, por exemplo, a ideia de que a criação e a criatividade já se encontravam anteriormente na potencialidade que se torna actual. Aqui, a criatividade é a articulação no agora da actualidade da anterior potencialidade.

Ora, temos de distinguir a potencialidade e identificá-la, não com a noção de um actual não formado, mas como um lado da distinção do sentido como a unidade entre actualidade e virtualização. O sentido processa assim diferenças, de maneira compulsiva, impondo uma determinada temporalidade gerada de forma auto-referencial sobre si próprio como meio. "O sentido refere-se sempre ao sentido e nunca vai para além de si próprio em direcção a outra coisa qualquer." ${ }^{36}$

No desassossego constitutivo do sentido, o movimento da forma faz-se sentir através de uma oscilação ${ }^{37}$ entre espaço marcado e não-marcado. Esta oscilação na forma cria espaço e tempo de maneira paradoxal. O tempo é criado pela oscilação de estados, que são criados por uma distinção. A distinção cria tempo através dos dois estados criados. E o tempo, "o primeiro tempo", como explica Spencer-Brown ${ }^{38}$, é medido pela oscilação entre estados. A única mudança que obtemos

${ }^{34}$ Sousa Dias, Lógica do Acontecimento - Introdução à Filosofia de Deleuze, Lisboa, Documenta, 2012, p.95.

${ }^{35}$ Este tipo de conceito está por detrás por exemplo do Movimento de Potencial Humano nos anos 70 do século XX, nos Estados Unidos da América.

${ }^{36}$ Niklas Luhmann, Social ..., cit., p.62.

${ }^{37}$ SPENCER-Brown fala mesmo que o livro Leis da Forma, entendido matematicamente, é uma "matemática do oscilador". Cf. GEorge SPENCER-Brown, "AUM Conference Transcript Session One. Esalen”, 1973 (http://www.lawsofform.org/ aum/session 1.html, consultado em: 2012.08.20).

${ }^{38}$ George Spencer-Brown, “AUM Conference..., cit. Spencer-Brown explica esta dinâmica auto-referencial apenas em termos de oscilação na secção "Time and Space". 
é o cruzamento do estado para outro. No entanto, o estado só pode ser espaço a partir do primeiro momento do desenho da distinção. Tanto o tempo como o espaço não têm frequência determinada. $O$ tempo não pode ser infinito, mas também não pode ser zero. E o espaço, determinado pela primeira distinção, não tem tamanho, distância, contorno, etc. O tempo "não tem duração. (...) Tal como o vazio não tem qualidade". ${ }^{39}$

\subsection{Possibilidade, impossibilidade e nada}

Assim quando desenhamos uma distinção, desenhamos sob este fundo que não é exprimível. A criação surge do nada enquanto vazio indiferenciável na diferenciação do seu surgimento. Não podemos caracterizar o surgimento da forma como possibilidade (potência), porque não existe antes do acto de a desenhar. Mas também não pode ser considerada uma actualidade, na medida em que a actualidade pressuponha uma possibilidade anterior na ordem do sentido.

Neste tipo de leitura, o possível é consequentemente enquadrado como uma figura lógica que delimita a actualização, como "figura ontológica primeira ou a primeira «razão» de todo o ser" ${ }^{40}$. E num sistema de sentido como unidade da diferença entre actualidadelpossibilidade, sendo que esta é operada como processamento de acordo a diferenças, para cada actualização existe um horizonte em excesso de possibilidades. Ora, essa actualização pode dar-se de possibilidade-em-possibilidade como elementos conectivos, como descrevemos acima, auto-propulsor da sua conectividade interna, através de um processo de selecção.

\subsection{A impossibilidade de uma criação no nada}

Aqui teremos de elaborar uma reentrada da distinção actualidadel Ipossibilidade, não na indicação da actualidade, mas no espaço da possibilidade. Esta reentrada abre a possibilidade para desenharmos as

\footnotetext{
${ }^{39}$ George Spencer-Brown, “AUM Conference..., cit.

${ }^{40}$ Sousa Dias, Grandeza de Marx - por uma política do impossível, Lisboa, Assírio \& Alvim, 2011.p.48, Cap.4.
} 
seguintes distinções possibilidadelactualidade e possibilidadelpossibilidade. Na primeira distinção, a actualidade de possibilidades seria de uma tal ordem de complexidade cujo processamento conectivo diluiria o sistema. Deixemos esta opção de lado. Na segunda, desenhar uma distinção e depois desenhar a mesma distinção no espaço não-marcado dá-nos o vazio (lei do cruzamento). Mas este vazio, em vez de ser um vazio como ausência ou como negatividade, é um vazio positivo, numa caracterização do medium do sentido, em muito semelhante à categoria de "caos" deleuziano ${ }^{41}$. É neste medium que surge a possibilidade da indicação de um novo conceito, para caracterizar este cruzamento que introduzimos agora: o conceito de impossibilidade.

A impossibilidade dá-se na lógica como sendo um conceito oposto ao da possibilidade; como sendo o seu contraditório, como aquilo que não pode nunca dar-se ou acontecer. Mas a impossibilidade, no contexto que estamos a criar, afecta a distinção da actualidadelpossibilidade, na medida em que afecta as condições de possibilidade, abrindo o conceito não para uma continuidade negativa do conceito de possibilidade, mas de "im-possível" (termo derridiano) como "condição ou a ocasião do possível"42; diríamos nós, como acontecimento ou evento.

A impossibilidade não é a realização da possibilidade, é uma criação simultaneamente de existência e de possíveis. E irrompe no sentido das condições de possibilidade das próprias condições de possibilidade, afectando a possibilidade da actualização da distinção da actualidadelpossibilidade. O surgimento desta impossibilidade faz apa-

41 "É um vazio que não é um nada [caracterizamos nós como: ausência, negativo] mas um virtual, contendo todas as partículas possíveis e extraindo todas as formas possíveis que surgem para de imediato desaparecerem, sem consistência nem referência, sem consequência.” Deleuze G. \& Guatari, F.. Qu'est-ce que la Philosophie?, Ed. De Minuit, 1991, p.101. sublinhado no original. Ora, não deixa de ser curioso a antipatia pelo termo "nada" na filosofia tradicional ocidental, com a dicotomia nada-vazio. Porque se formos investigar, o "nada", etimologicamente, vem de natta "coisa nascida", e que é da expressão latina "res [non] nata", com o eclipse do non e perda do res, passou a significar "coisa alguma", "nada".

${ }^{42}$ JACQUES DERRIDA, «Cierta posibilidad imposible de decir el acontecimiento», in Jacques Derrida, Gad Sussana, Alexis Nouss, Decir el acontecimiento, es posible?, 2001, Arena Libros, Madrid, pp. 97-98, realizado no Centro Canadiense de Arquitectura, 1. ${ }^{\circ}$ de Abril de 1977, tradução de Julián Santos Guerrero, Edición digital de Derrida en castellano (http://jacquesderrida.com.ar/textos/decir_el_ acontecimiento.htm, consultado em: 2012.02.25). 
recer aquilo que nunca poderia aparecer como simples possibilidade. Esta criação transforma aquilo que podemos em potência observar num certo conjunto de formas actualidadelpossibilidade. Seja que termo essa transformação se designar por um observador, esta "irrupção", "extravasão", "transubstanciação", "êxtase", no seu surgimento, surge como um todo que tem como efeito não decorrer do ser como causa, mas retroactivamente gerar uma aura ao adequar-se como pressão determinante dessa criação, organizando os elementos que fazem parte como substrato, como húmus, com os seus elementos efectivos, isto é, a sua concretude material na sua memória, corpo ${ }^{43}$, instrumentos e relações. Como nos diz Sousa Dias, esse "acontecimento cria a sua própria possibilidade como possibilidade no ser”. Quando esta transformação se dá, a observação parece-lhe conferir validade $a$ priori, parece que "fazia todo o sentido o surgimento desta criação", sendo que não é possível evitar este tipo de efeito descritivo por retrocesso ${ }^{44}$, ao surgir ele mostra-se possível como de facto, torna-se possível a partir daí, fazer considerandos como "faz sentido que tal e tal aparecesse", característico de uma espécie de discurso descritivo a posteriori.

\subsubsection{A transformação e linguagem paradoxal}

Estamos, desde o parágrafo anterior, em terreno perigoso. A verdade é que estamos a entrar num território em que uma das funções da linguagem (a saber, a função descritiva da linguagem no âmbito da criatividade fechando as possibilidades em processos serializados ou santificados de actualizações e ou potenciais), que utilizamos como pressuposição neste ensaio, começa a entrar num certo tipo de falência. Dentro desta função as contradições e paradoxos da criação como impossibilidade tornam-se uma das maneiras de a caracterizar, pois,

\footnotetext{
Grácio.

${ }^{44}$ Jorge Luís Borges, no seu ensaio "Kafka e os Seus Precursores" fala precisamente de como os chamados grandes escritores criam os seus precursores. Os nexos descritivos relativos a influências, estilos, ou genialidade atribuem-se depois, a posteriori, como efeito da obra.
}

${ }^{43}$ Agradeço este ponto, sobre memória e corpo, da discussão com Ricardo 
parafraseando Werner Erhard ${ }^{45}$, quando a transformação acontece esta é nada - ou tudo. Se ela ocorre, não ocorre. E se ocorre, então sempre ocorreu.

Este tipo de linguagem com base em paradoxos e contradições pode ofender uma leitura mais logicista, mas se uma pessoa afirmar que $a$ criação é transformação, a sua justificação prosseguirá descrevendo que a mesma vem do nada que é tudo, enquanto oscilação e embate na qual brota a possibilidade do impossível não possivel, enquanto singularidade evanescente. Por outro lado, no limite desta função descritiva, podemos ainda cruzá-la para, tal como certos místicos, o nada, o silêncio descritivo sobre a criação. Mas como vimos, neste nada está tudo, e é impossível descrever tudo.

\subsection{Criação e contemporaneidade}

Em suma, o que vemos aqui, no ponto de vista do sistema psíquico para a nossa época contemporânea, é o descentramento daquilo que podemos designar de "formas canónicas" 46 da criação. Estas formas, que encaixavam certas visões de um sistema psíquico com uma identidade extraordinária, como um génio, ou privilegiado por algum tipo de percurso de carácter cognitivo ou técnico (por exemplo, quem tem mais estudos, ou saber mais coisas, ou tem maior talento, ou é melhor trabalhador, ou é mais versátil, etc., é criativo), para um enquadramento de uma possibilidade do sistema psíquico de âmbito oscilante, capaz, num instante de impossibilidade, criar a todo o momento ou em nenhum momento, por assim dizer. Não é aconselhável, nem possível, rejeitar as descrições sobre a criatividade e o seu valor enquanto processos e materiais, e seria um movimento discriminatório fazê-lo. Mas a outra face, a face que criámos aqui neste texto, (ex)põe a criação como acontecimento, ordenando-nos: "Desenha uma distinção!"

45 Werner Erhard \& Victor Gioscia, "Epistemological And Contextual Contributions of est to General Systems Theory", apresentado em Evolving Trends in General Systems Theory and the Future of the Family at the Sixth World Congress of Social Psychiatry, Opatija, Yugoslavia, 5 Outubro 1976, (http://www.werne rerhard.net/epistemological.html, consultado em: 2013-03-07).

${ }^{46}$ Agradeço ao Ricardo Grácio este conceito. 